\title{
9p DELETION AND DISTAL 9q DUPLICATION DUE TO A PATERNAL PERICENTRIC INVERSION 9(p22q32)
}

\author{
Tohru Sonoda, ${ }^{1}$ Ken-ichi OHBa, ${ }^{1}$ Shozo OHdo, ${ }^{1}$ \\ and Koji SAMESHIMA ${ }^{2}$ \\ ${ }^{1}$ Department of Pediatrics, Miyazaki Medical College, \\ Kiyotake-cho, Miyazaki 889-16, Japan \\ ${ }^{2}$ Department of Pediatrics, Faculty of Medicine, Kagoshima University, \\ Usuki-cho, Kagoshima 890, Japan
}

\begin{abstract}
Summary A female infant with $46, \mathrm{XX}, \operatorname{rec}(9)$, dup $\mathrm{q}, \operatorname{inv}(9)(\mathrm{p} 22 \mathrm{q} 32)$ pat is presented. She had a duplication from $9 \mathrm{q} 32$ to qter and a deletion from 9 p22 to 9 pter. Phenotypical abnormalities observed corresponded with features noted in cases with distal dup ( $9 q)$, while pathognomonic features of del $(9 \mathrm{p})$ syndrome were not observed.
\end{abstract}

Key Words chromosome 9, pericentric inversion, recombinant chromosome, duplication-deletion

\section{INTRODUCTION}

Only one case of unbalanced offspring born from a carrier with a pericentric inversion of chromosome 9 has been reported (Mattei et al., 1980). Here we present an additional case with a recombinant chromosome in a pericentric inversion of chromosome 9 with break points in $9 \mathrm{p} 22$ and $9 \mathrm{q} 32$, and discuss clinical features associated with the occurrence of this abnormal chromosome.

\section{CLINICAL AND CYTOGENETIC FINDINGS}

The proband, a female, was born August 22, 1989 after 41 weeks' gestation, being the 4th pregnancy of healthy and unrelated parents. The father was 36 and the mother was 34 years old at the time of her birth. The mother's first two pregnancies ended in spontaneous abortions at first trimester. The third pregnancy which resulted in a spontaneous abortion at 6 th month was a multiple pregnancy of one boy and two girls. Although an abnormality was noted in one of the eyes of the boy, other details were not known. Due to irregularities of menstruation and ovulation, the mother had taken an ovulation stimulator for the period before

Received August 17, 1990; revised version received October 4, 1990; Accepted January 22, 1991. 
conception of the proband until 4th month of gestation. Birth weight of the proband was $2,320 \mathrm{~g}$. Due to heart murmur and multiple minor anomalies, she was referred to our outpatient clinic at the age of 2 months. At this time weight was $3,620 \mathrm{~g}$ ( -2.8 S.D.), length $55.5 \mathrm{~cm}$ (-1.1 S.D.), and head circumference $38.0 \mathrm{~cm}$ (almost average). Facial appearance was peculiar, containing the following craniofacial dysmorphisms: dolichocephaly, frontal bossing, widow's peak, smooth and thick hair, portwine mark $(5$ by $5 \mathrm{~cm}$ ) at the parietal region, absence of the scalp ( 1.5 by $1.5 \mathrm{~cm}$ ), deep-set eyes, short and horizontal palpebral fissures, beaked nose, small mouth, thin and overhanging upper lip, high-arched palate, small, pointed and receding chin, and right preauricular skin tag. Ears were normal in shape, size and position. Heart murmurs were audible, and the skin over the whole body was eczematous. Contracture of hip joints was recognized. Fingers were slender and long, and camptodactyly of the left third finger was noted. Toes were also long. Dermatoglyphic study revealed 4 whorls, 4 ulnar loops, and 2 radial loops on the fingers. The atd angle was $110^{\circ}$ on the right palm and $100^{\circ}$ on the left.

Echocardiography showed secundum atrial septal defect. Chromosomes of the patient and those of her parents were analyzed on cultured lymphocytes. The father's karyotype was 46,XY,inv(9)(p22q32) and the karyotype of the proband was $46, X X, \operatorname{rec}(9)$, dup $\mathrm{q}$, inv(9)(p22q32)pat, representing a duplication of the distal portion $9 \mathrm{q}(9 \mathrm{q} 32 \rightarrow \mathrm{qter})$ and a deletion of $9 \mathrm{p}(9 \mathrm{p} 22 \rightarrow \mathrm{pter})$ (Figs. 1 and 2 ). The mother's karyotype was normal. Aborted fetuses were not karyotyped. Studies of $\mathrm{ABO}$ blood group were not informative since the father, mother and proband all presented the group $O$ type.

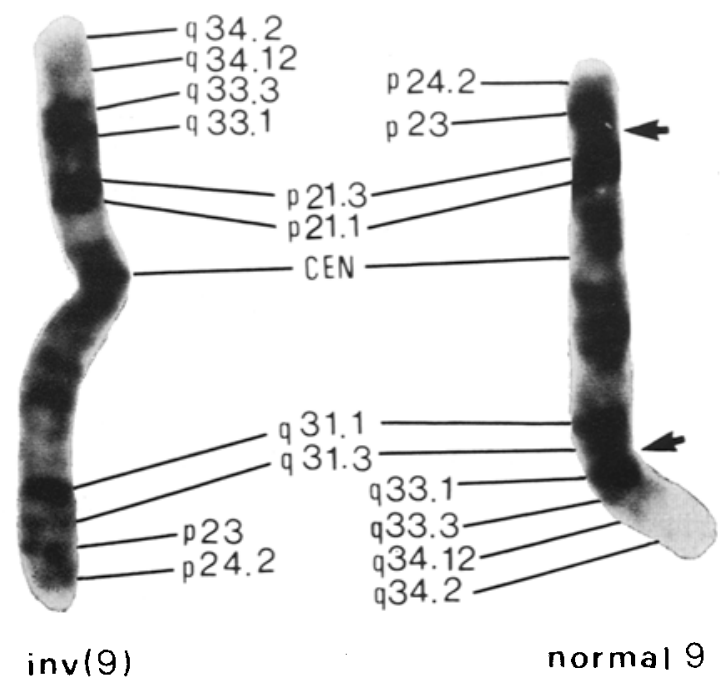

Fig. 1. Partial karyotype of the father. Arrows indicate the break points of $9 \mathrm{p} 22$ and 9q32, respectively. 


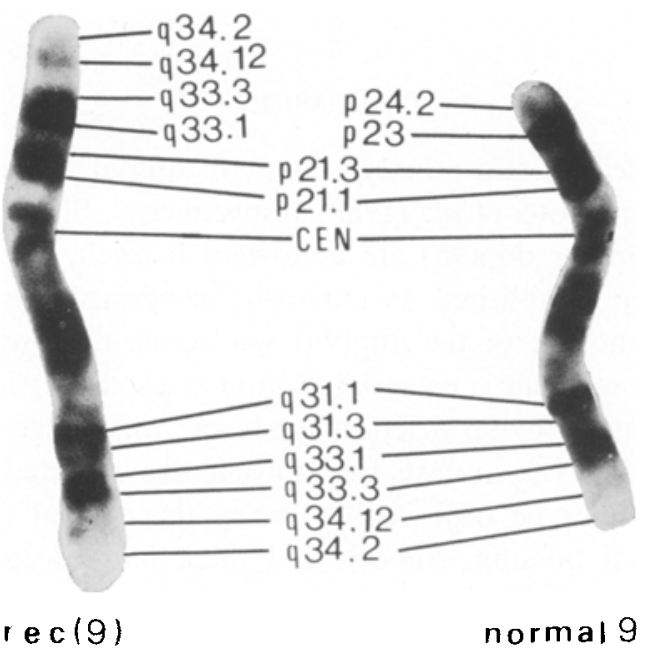

Fig. 2. Partial karyotype of the proband.

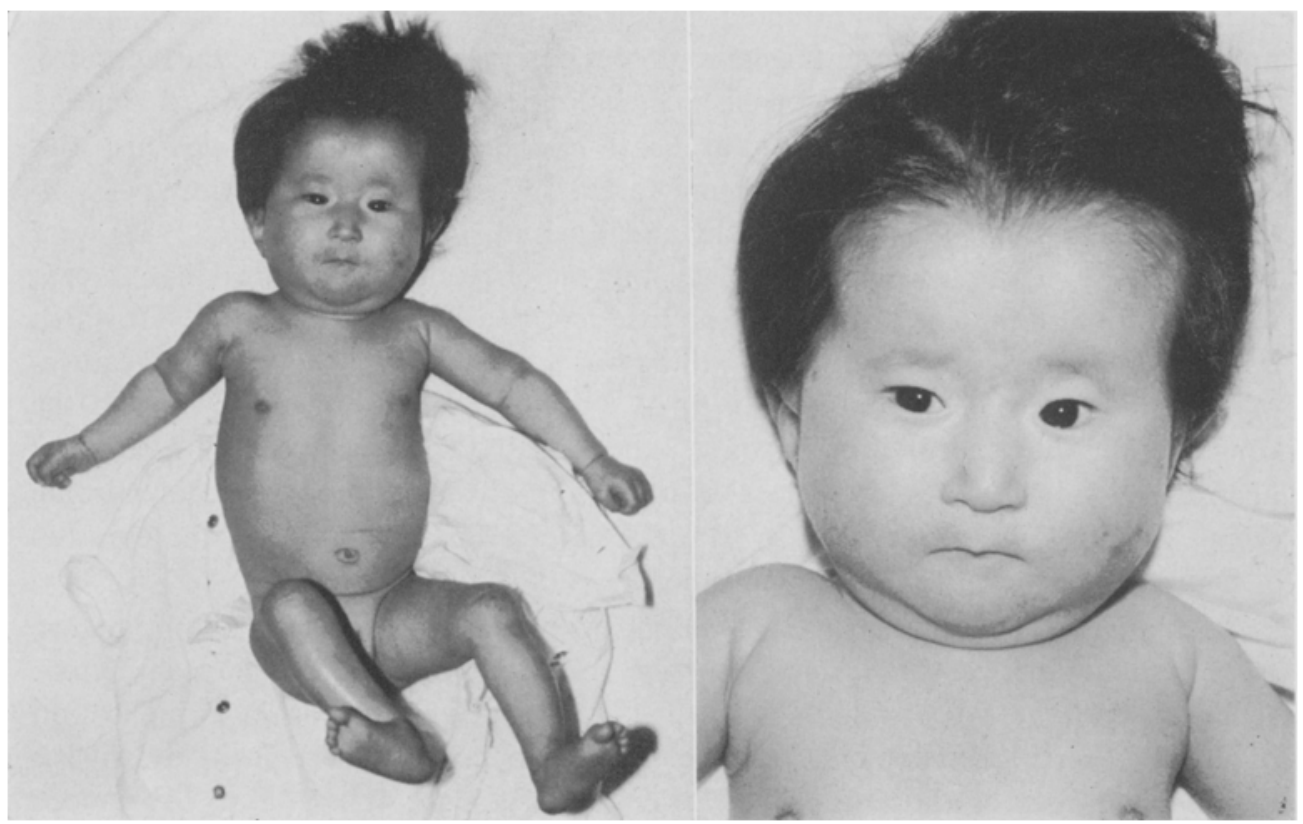

Fig. 3. Proband at 7 months.

At the age of 7 months, weight was $5.1 \mathrm{~kg}(-3.6$ S.D.), length $64.8 \mathrm{~cm}(-1.5$ S.D.) and head circumference $43.0 \mathrm{~cm}$ (almost average), and DQ was about 40 (Fig. 3). 


\section{DISCUSSION}

Eighty cases of del( $(9 p)$ and nineteen cases of $\operatorname{dup}(9 q)$ were reviewed by Huret et al. (1988) and Yamamoto et al. (1988) respectively. Since the clinical findings of patients with $\operatorname{del}(9 \mathrm{p})$ or $\operatorname{dup}(9 \mathrm{q})$ are consistent in each, these chromosomal abnormalities have been established as clinically recognizable syndromes. For the expression of the phenotype of the $\operatorname{dup}(9 q)$ syndrome, the presence of duplication of $9 \mathrm{q} 32$ or $34.1 \rightarrow$ qter segment is essential (Solton et al., 1984; Houdou et al., 1987), while the critical segment for $9 p$ deletion syndrome was suggested to be within the band 9p24 (Hoo, 1986). In our case, therefore, it was expected that the phenotypes of both syndromes might be observed. Among the clinical features in our case, dolichocephaly, frontal bossing, smooth and thick hair, deep-set eyes, horizontal palpebral fissures, beaked nose, and overhanging upper lip were characteristic for the dup(9q) syndrome (de Grouchy and Turleau, 1984; Solton et al., 1984; Yamamoto et al., 1988). Although growth and developmental retardation, small mouth, micrognathia, high-arched palate, long fingers and toes, and heart disease are features noted in both $9 p-$ and dup(9q) syndromes (de Grouchy and Turleau, 1984), none of them, excluding long fingers and toes, are pathognomonic. Furthermore, characteristic craniofacial dysmorphism including trigonocephaly, upward slanting palpebral fissures, long philtrum, flat nasal bridge, and anteverted nostrils, and square and hyperconvex nails which are rather specific among cases with $9 \mathrm{p}-$ syndrome (Young et al., 1982; de Grouchy and Turleau, 1984; Huret et al., 1988) were not observed in our case. Accordingly the majority of the features in our case might be those due to dup (9q). In the case reported by Mattei et al. (1980) which had the similar karyotype to our case, there was a greater similarity with the features of dup(9q) syndrome than those of $9 p-$ syndrome. Those findings support the concept that the cinical features of a patient with two concurrent chromosomal aberrations are not necessary to be the summation of the features of each syndrome (Hoo, 1986). Our case as well as Mattei's case (1980) demonstrates the epistasis of $\operatorname{dup}(9 \mathrm{q})$ syndrome over $9 \mathrm{p}-$ syndrome.

As an explanation for the small numbers of $\operatorname{del}(9 p)$ and $\operatorname{dup}(9 q)$ originating from parental pericentric inversion 9 , the following reasons can be considered: 1) Fertility of the carrier parent is low; 2) crossing-over resulting in a duplication of $9 q$ in one recombinant chromosome and of $9 p$ in the other inevitable will be rare; 3 ) frequency of abortion in the carrier parent is high; 4) even if an unbalanced offspring is born, it dies earlier before being karyotyped; and 5) the number of carriers of this type of inversion is actually small.

There are few reports in which an association between infertility and inversion was found (Jacobs et al., 1975; Moorhead, 1976; Carpenter et al., 1982). Relatively normal reproductive capacity of the carriers of inversions (9)(p11q13)[inv(9)(qh)] has been found (De la Chapella et al., 1974). Judging from our pedigree, 
we cannot say that the fertility of the carrier father is low.

In general, the probability for production of unbalanced gamates, i.e. the crossing-over possibilities, depends on the proximity of the breakpoints to the centromere (Stene, 1986). So far we have not seen any report of unbalanced offspring from carriers of inv(9)(qh). It is speculated that recombination does not occur because of the short distance between the two breakpoints, and because of the centromere and heterochromatic block (Boué et al., 1975; Martin and Abrisqueta, 1983). In the father of our proband, the breakpoint is located at a distal portion far from the heterochromatic region, so there is ample possibility of the occurrence of crossing-over.

It has been found that the relative risk of inv(9)(qh) positive couples having spontaneous abortions compared to inv(9)(qh) negative couples is not significantly increased statistically (De la Chapella et al., 1974; Campana et al., 1986). In the father of our proband the inverted segment was so large that the frequency of abortion might be low. The three spontaneous abortions observed in our family might have been by chance.

The unbalanced gamate types expected from a carrier of pericentric inversion would possess a duplication of long arm genes and deletion of short arm genes (as in our case) and the opposite unbalanced karyotype. Although life expectancy of combinations of each chromosomal aberration, and the deletion of the long arm is unknown, the individual survival probabilities of deletion $9 \mathrm{p}$, duplication $9 \mathrm{p}$, and duplication 9q are not particularly low (Alfi et al., 1976; Schinzel, 1984; de Grouchy and Turleau, 1984; Nakahori and Nakagome, 1984).

According to the European Collaborative Study, excluding pedigrees with inversions in the heteromorphic regions, such as the common variant inv(9)(p11q13), no pedigree was noted in inversions containing chromosome 9 among 91 pedigrees with pericentric inversion (Boué and Gallano, 1984). According to Sherman et al. (1986), in a review of a total of 216 pedigrees with pericentric inversions, only 3 pedigrees (9p24q13,9p22q32 and 9p24q12) were discovered. It is estimated that the real number of carriers of the pericentric inversion of chromosome 9 found in our pedigree is quite small.

\section{REFERENCES}

Alfi, O., Donnell, G.N., Allderdice, P.W. and Derencsenyi, A. 1976. The 9p-syndrome. Ann. Génét. 19: 11-16.

Boué, J., Taillemite, J.L., Hazael-Massieux, P., Léonard, C. and Boué, A. 1975. Association of pericentric inversion of chromosome 9 and reproductive failure in ten unrelated families. Hum. Genet. 30: 217-224.

Boué, A. and Gallano, P. 1984. A collaborative study of the segregation of inherited chromosome structural rearrangements in 1356 prenatal diagnoses. Prenat. Diagn. 4 (Spec. Iss.): 45-67.

Campana, M., Serra, A. and Neri, G. 1986. Role of chromosome aberrations in recurrent abortion: A study of 269 balanced translocations. Am. J. Med. Genet. 24: 341-356.

Carpenter, N.J., Say, B. and Barber, N.D. 1982. A homozygote for pericentric inversion of chro-

Vol. 36, No. 1,1991 
mosome 4. J. Med. Genet. 19: 469-471.

de Grouchy, J. and Turleau, C. 1984. Clinical Atlas of Human Chromosomes. 2nd Ed., John Wiley \& Sons. New York.

De la Chapella, A., Schröder, J., Stenstrand, K., Fellman, J., Herva, R., Saarni, M., Anttolainen, I., Tallila, I., Tervilä, L., Husa, L., Tallquvist, G., Robson, E.B., Cook, P.J.I. and Sanger, R. 1974. Pericentic inversion of human chromosome 9 and 10. Am. J. Hum. Genet. 26: $746-766$.

Hoo, J.J. 1986. Critical segment for 9p deletion syndrome. Clin. Genet. 29: 541-542.

Houdou, S., Yorifuji, T., Tsuruta, S., Hashida, K., Ohta, S. and Ieshima, A. 1987. Distal 9q trisomy syndrome: Report of the first oriental case and literature review. Acta Neonatal Japonica 23: 347-352.

Huret, J.L., Leonard, C., Forestier, B., Rethoré, M.O. and Lejeune, J. 1988. Eleven new caess of del(9p) and features from 80 cases. J. Med. Genet. 25: 741-749.

Jacobs, P.A., Frackiewicz, A., Law, P., Hilditch, C.J. and Morton, N.E. 1975. The effect of structural aberrations of the chromosomes on reproductive fitness in man. II. Results. Clin. Genet. 8: 169-178.

Martin, M.J. and Abrisqueta, J.A. 1983. Unusual pericentric inversion inv(9)(p13q11) in a phenotypically normal family. Hum. Genet. 62: 100.

Mattei, J.F., Mattei, M.G., Ardissone, J.P., Taramasco, H, and Giraud, F. 1980. Pericentric inversion, inv(9)(p22q32), in the father of a child with a duplication-deletion of chromosome 9 and gene dosage effect for adenylate kinase-1. Clin. Genet. 17: 129-136.

Moorhead, P.S. 1976. A closer look at chromosomal inversions. Am. J. Hum. Genet. 28: 294296.

Nakahori, T, and Nakagome, Y. 1984. A malformed girl with duplication of chromosome $9 . J$. Med. Genet. 21: 387-388.

Schinzel, A. 1984. Catalogue of Unbalanced Chromosome Aberrations in Man. Walter de Gruyter New York, pp. 350-394.

Sherman, S.L., Iselius, L., Gallano, P., Buckton, K., Collyer, S., DeMey, R., Kristoffersson, U., Lindosten, J., Mikkelsen, M., Morton, N.E., Newton, M., Nordensson, I., Petersen, M.B. and Wahlström, J. 1986. Segregation analysis of balanced pericentric inversions in pedigree data. Clin. Genet. 30: 87-94.

Solton, H.C., Jung, J.H., Pyatt, Z. and Singh, R.P. 1984. Partial trisomy 9q resulting from a familial translocation $\mathrm{t}(9 ; 16)(\mathrm{q} 32 ; \mathrm{q} 24)$. Clin. Genet. 25: 449-454.

Stene, J. 1986. Comments on methods and results in: Sherman et al, "Segregation analysis of balanced pericentric inversions in pedigree data." Clin. Genet. 30: 95-107.

Yamamoto, Y., Oguro, N., Nara, T., Horita, H., Niitsu, N. and Imaizumi, S. 1988. Duplication of part of $9 \mathrm{q}$ due to maternal $12 ; 9$ inverted insertion associated with pyloric stenosis. Am. J. Med. Genet. 31: 379-384.

Young, R.S., Reed, T., Hodes, M.E. and Palmer, C.G. 1982. The dermatoglyphic and clinical features of the $9 \mathrm{p}$ trisomy and partial $9 \mathrm{p}$ monosomy syndrome. Hum. Genet. 62: 31-39. 